\title{
DARI FEDERALIS KE UNITARIS: STUDI KASUS SULAWESI SELATAN 1945-1950
}

\author{
Oleh Muhammad Amir \\ Balai Pelestarian Sejarah dan Nilai Tradisional Makassar \\ Kementerian Kebudayaan dan Pariwisata \\ Jalan Sultan Alauddin / Tala Salapang Km 7 Makassar 90221 \\ Telp. (0411) 885119 Fax. (0411) 865166, 883748 \\ Email: muhammad_amir66@rocketmail.com \\ Naskah diterima: 15 April 2010 \\ Naskah disetujui: 30 Mei 2010
}

\begin{abstract}
Abstrak
Kajian ini bertujuan untuk mengungkapkan dan menjelaskan latar belakang dan proses perubahan sistem ketatanegaraan dari federalis ke unitaris di Sulawesi Selatan 1945-1950. Metode yang digunakan dalam kajian ini adalah metode sejarah, yang menjelaskan persoalan penelitian berdasarkan perspektif sejarah. Prosedurnya meliputi empat tahapan, yaitu pencarian dan pengumpulan sumber (heuristik), kritik sumber (seleksi data), interpretasi (penafsiran), dan penyajian atau penulisan sejarah (historiografi). Hasil kajian menunjukkan bahwa pembentukan Negara Indonesia Timur (NIT) bukan semata-mata kehendak Belanda, melainkan juga keinginan sebagian masyarakat yang menghendaki negara Indonesia berbentuk federal. Negara federal diyakini tidak hanya sesuai dengan kondisi Indonesia yang terdiri atas beberapa pulau, etnis, dan budaya, tetapi juga akan memberikan kesempatan luas kepada pemerintah tiap-tiap negara bagian untuk mengelolah potensi wilayahnya masing-masing. Namun upaya untuk mempertahankan eksistensi NIT, kalah bersaing dengan semangat unitaris, sehingga melapangkan terwujudnya kembali Negara Kesatuan Republik Indonesia.
\end{abstract}

Kata kunci: federalis, unitaris, dan otonomi.

\begin{abstract}
This study is intended to uncover and find out background and change process of governance system from federalism to unitarian in South Sulawesi 1945-1950. Method used in this research is historical method, which explainsresearch problem based on historical perspective. Its procedure includes four steps, finding and collecting data (heuristic), source critique (data selecting), interpretation, and historiography. Result of analysis shows that the establishment of East Indonesian Nation is not merely Netherlands desire, but also the desire of certain community that intends to form federal nation of Indonesia. Federal nation is considered not only appropriate with Indonesian's state consisting of many island, ethnics, and cultures, but also will give widely opportunity to the government of each state to manage their own potential area. Yet, the effort to preserve the existence of East Indonesian Nation is more dominitaed by unitarian spirit, then it makes esay the establishment of Republic of Indonesian Nation.
\end{abstract}

Keywords: federalism, unitarian, and autonomy. 


\section{A. PENDAHULUAN}

Setelah proklamasi kemerdekaan Indonesia, Belanda bergegas kembali ke Indonesia. Kehadirannya itu mendapat penolakan dari sebagian besar rakyat Indonesia, sehingga H. J. van Mook, wakil pemerintah Belanda di Indonesia merancang suatu strategi politik untuk memulihkan kembali kedudukan kekuasaan pemerintah kolonial Belanda di wilayah bekas jajahannya (Hindia Belanda), termasuk di Sulawesi Selatan. Strategi politik itu dikenal dengan gagasan negara federal. Atas kebijakan Sekutu yang menempatkan NICA (Netherlands Indische Civil Administratie) sebagai bagian integral dari pasukan Australia (wakil Sekutu) di Sulawesi Selatan, aparat-aparat NICA berhasil mempengaruhi sebagian tokoh politik dan raja-raja di daerah ini untuk bekerjasama guna mewujudkan gagasan negara federal. Gagasan itu secara resmi dibicarakan dalam Konferensi Malino pada bulan Juli 1946. Seiring dengan tercapainya persetujuan Linggarjati, gagasan negara federal semakin mendapat angin segar. Persetujuan Linggarjati mengisyaratkan pembentukan negara federal Indonesia, kelak akan terdiri atas Republik Indonesia, Borneo, dan Timur Besar (Groote Oost). Gagasan itu akhirnya terwujud menjadi kenyataan dalam Konferensi Denpasar, yang ditandai dengan terbentuknya Negara Indonesia Timur (NIT) pada tanggal 24 Desember 1946 (Agung, 1992: 38).

Sejak awal proses pembentukan

NIT, sesungguhnya telah diwarnai oleh konflik politik antara mereka yang menghendaki bentuk negara kesatuan dengan mereka yang menghendaki bentuk negara federal, yang kemudian lebih dikenal dengan konflik politik antara kelompok unitaris dan federalis. Bagi kelompok unitaris, pembentukan negara-negara federal merupakan taktik dan strategi pemerintah Belanda untuk menguasai kembali wilayah bekas Hindia Belanda dan sekaligus menghancurkan Republik Indonesia. Sedangkan kelompok federalis memandang bahwa bentuk negara federal merupakan sistem kenegaraan yang tepat untuk Indonesia mengingat keadaan geografis, dan corak kebudayaan yang beraneka ragam. Konflik politik antara kedua kelompok itu terus berlanjut hingga berakhirnya riwayat NIT, yang kemudian melebur ke dalam Negara Kesatuan Republik Indonesia.

Bertolak dari uraian singkat tersebut, maka yang menjadi permasalahan kajian ini adalah bagaimana latar belakang dan proses pembentukan NIT serta eksistensinya hingga berubah menjadi negara kesatuan. Perubahan sistem ketatanegaraan dari federalis ke unitaris yang mewarnai perjalanan sejarah Sulawesi Selatan 1945-1950, perlu diungkapkan dan dijelaskan secara utuh. Oleh karena perubahan yang terjadi selama Perang Kemerdekaan itu, tidak hanya patut untuk direnungkan dan dipahami, tetapi juga bijaksana untuk berdialog dengan masa lampau itu; membuka diri secara jujur dan penuh toleransi, agar kita dapat menjadi lebih arif dan bijaksana di dalam membangun kekinian dan hari esok. 


\section{B. HASIL DAN PEMBAHASAN}

\section{Latar Belakang dan Proses Pembentukan NIT}

Perang Pasifik Raya yang berakhir tanggal 14 Agustus 1945, mendorong Belanda kembali ke Indonesia untuk memulihkan kembali kedudukan kekuasaan pemerintahan kolonialnya. Kenyataan yang dijumpai adalah terbentuknya Negara Kesatuan Republik Indonesia yang telah diproklamasikan tanggal 17 Agustus 1945. H. J. van Mook yang menjadi wakil pemerintah Belanda di Indonesia, kemudian merencanakan membentuk strategi "politik federal" (federale politiek), yang mendapat sambutan baik dari pemerintah Belanda. Pengumuman strategi itu disampaikan pada tanggal 10 Februari 1946, yang pada intinya menyatakan bahwa rakyat Indonesia kelak dapat memutuskan secara bebas masa depan politiknya sendiri setelah melalui periode persiapan tertentu, dimana selama itu Indonesia menjadi negara bagian dari Nederland (Ijzereef, 1984: 1).

Tawaran pemerintah Belanda itu kurang mendapat dukungan rakyat Indonesia, sehingga van Mook merancang strategi untuk memenangkan pengaruh Belanda terhadap daerah di luar Jawa, Madura dan Sumatra, khususnya Kalimantan dan Timur Besar (termasuk Bali dan Lombok). Pilihan itu kemudian dijatuhkan pada Sulawesi Selatan yang direncanakan sebagai pusat NIT (Negara Indonesia Timur) dengan ibukota Makassar. Daerah ini, berdasarkan ordonansi tahun 1936 No. 68 telah menjadi pusat wilayah "Governement van Grote Oost" (Pemerintahan Timur Besar) yang berstatus otonom dengan meliputi wilayah Sulawesi, Maluku, Irian Barat, Kepulauan Sunda Kecil dan Pulau Bali (Staatsblad 1936 No. 68; Poelinggomang, 1995: 3).

Van Mook dalam mewujudkan strategi politiknya itu mengemukakan alasan dan pemikiran yang dapat diterima oleh tokoh masyarakat sehubungan dengan rencana pembentukan NIT, antara lain bahwa dalam bentuk negera federal dapat dijamin kehidupan dari segenap golongan. Dengan demikian dapat ditempatkan suatu pembagian tugas yang terdapat antara pemerintah pusat dan daerah (Kementerian Penerangan, 1953: 80). Sebagian tokoh-tokoh politik dan raja-raja di Sulawesi Selatan menyambutnya dengan pertimbangan lain dari skenario Belanda, yaitu menjadikan negara federal NIT untuk menghapus sistem pemerintahan yang sentralistik dan memajukan daerah berdasarkan kemampuan sendiri. Mereka ingin menjadikan NIT sebagai negara bagian dari negara Indonesia Serikat dengan otonomi yang luas, agar supaya NIT dapat mengatur rumah tangganya sendiri. Sebab, dengan otonomi yang luas kemungkinan kesejahteraan masyarakat lebih dapat terjamin. Namun bagi pemerintah Belanda, pembentukan negara federal merupakan suatu taktik dan strategi untuk menguasai kembali wilayah Hindia Belanda dan sekaligus menghancurkan dan melumpuhkan Republik Indonesia (Harvey, 1990: 228).

Mengapa orang-orang nasionalis yang terkemuka setuju untuk bekerjasama dengan Belanda dalam NIT ? G.R. Pantouw yang bekerja dengan Dr. Ratulangi dalam Sudara (organisasi 
perjuangan kemerdekaan masa Jepang) dan PKR (Pusat Keselamatan Rakyat) sebelum menjadi menteri penerangan kabinet NIT pertama, menjelaskan bahwa ia dan Nadjamuddin Daeng Malewa bekerjasama dengan van Mook dalam bidang ekonomi karena melihat rakyat sudah cukup menderita akibat penjajahan Jepang. Mereka berpendapat bahwa melawan Belanda secara fisik adalah perbuatan sia-sia, maka ia dan Nadjamuddin mendesak van Mook agar secepatnya membentuk NIT (Harvey, 1990: 226). Pengakuan Pantouw ini memberikan penjelasan bahwa NIT dibentuk bukan sematamata kehendak Belanda, melainkan timbul dari kesadaran sebagian masyarakat yang menginginkan negara Indonesia berbentuk federal. Mereka percaya bahwa bentuk negara federal akan memberikan kesempatan luas kepada pemerintah tiap-tiap negara bagian untuk mengelolah potensi wilayahnya masing-masing.

NIT yang akan berdiri sebagai satu negara bagian merupakan sarana untuk mencapai kesejahterakan rakyat. Perbedaan kondisi dan potensi yang dimiliki antara pulau Jawa dan pulaupulau di luar Jawa merupakan dasar pemikiran utama pembentukan NIT. Misalnya, dari segi jumlah penduduk, pendidikan dan kebudayaan, Jawa lebih maju dibanding dengan pulau-pulau di luar Jawa. Bahkan ada kekhawatiran bahwa orang Jawa yang berjumlah jauh lebih besar, secara politik akan mendominasi Indonesia yang merdeka (Harvey, 1990: 223). Oleh karena itu, salah satu tujuan dibentuknya NIT adalah untuk membendung bahaya ekspansi Jawa dan sentralisasi administrasi dari pusat (Jakarta), sebagaimana diketahui bahwa Jakarta waktu itu merupakan pusat penyelenggaraan pemerintahan Republik Indonesia.

Pembicaraan tentang

pembentukan NIT dimulai di dalam Konferensi Malino pada bulan Juli 1946. Dalam pertemuan yang dihadiri oleh pihak Belanda dan wakil-wakil dari wilayah Indonesia Timur itu, timbul perdebatan serius tentang bentuk negara dari peserta konferensi. Ada kelompok yang menghendaki bentuk negara federal, sedangkan yang lainnya menginginkan bentuk negara kesatuan (unitaris). Perbedaan pendapat dari kedua kelompok ini dilatarbelakangi oleh pandangan politik masing-masing. Kelompok federalis melihat bahwa bangsa Indonesia terdiri atas beberapa kelompok etnis yang mempunyai ciri budaya masingmasing, di samping itu sifat-sifat ekonomi yang berbeda antara pulau Jawa dengan pulau-pulau di luar Jawa. Sementara kelompok unitaris melihat bahwa bangsa Indonesia adalah bekas jajahan Belanda yang mempunyai perasaan historis yang sama (Harvey, 1984: 10). Van Mook berusaha mempengaruhi peserta konferensi tentang kemungkinan yang akan terjadi jika membentuk sistem unitaris, yaitu terjadinya keinginan dari suatu kelompok tertentu untuk menguasai atau memaksakan keinginanannya kepada kelompok lain, yang pada gilirannya mengundang terjadinya perpecahan. Van Mook menyarankan peserta agar menerima sistem federal dengan syarat bahwa bagian-bagian dari federasi itu haruslah merupakan wilayah-wilayah yang luas, mempunyai potensi ekonomi, sosial dan politik 
yang cukup mantap. Dengan demikian setiap federasi akan menunjang federasi Indonesia menjadi satu kesatuan yang kuat (Agung, 1985: 104).

Konferensi Malino kemudian disusul dengan Perundingan Linggarjati antara pemerintah Republik Indonesia yang diwakili Sutan Syahrir dengan pemerintah Belanda yang diwakili oleh Komisi Jenderal di bawah ketua Prof. Schermerhorn yang dimulai pada tanggal 12 November 1946. Hasil perundingan yang diparaf pada tanggal 15 November 1946, mengisyaratkan pembentukan negara federal Indonesia, yang kelak akan terdiri atas Republik Indonesia, Borneo, dan Timur Besar,. Dengan tercapainya persetujuan itu, maka dilangsungkan Konfensi Denpasar untuk mendirikan suatu sistem ketatanegaraan di dalam lingkungan negara Indonesia yang merdeka dan berdaulat sesuai dengan Persetujuan Linggarjati. Pada tanggal 24 Desember 1946 berdirilah Negara Indonesia Timur (NIT) dengan ibukota Makassar yang mencakup wilayah di Indonesia bagian timur, yang di dalam masa penjajahan Belanda dikenal dengan nama Timur Besar (Grote Oost). Tjakorde Gde Rake Soekawati terpilih menjadi Presiden NIT yang pertama, Tadjoeddin Noor kemudian dipilih menjadi ketua parlemen NIT, dan Nadjamuddin Daeng Malewa dari Sulawesi Selatan sebagai formatur kabinet pertama NIT (Agung, 1992: 38).

Setelah Konferensi Denpasar ditutup, Presiden Soekawati bersama formatur kabinet Nadjamuddin Daeng Malewa, berangkat ke Jakarta untuk melakukan pembicaraan dengan pemerintah Belanda menyangkut pem- bentukan kabinet pertama NIT. Akhirnya Nadjamuddin Daeng Malewa berhasil menyusun kabinetnya yang terdiri dari sembilan menteri yang masing-masing mengepalai satu kementerian dan dilantik oleh Presiden NIT Soekawati di Jakarta pada tanggal 13 Januari 1947, yang dihadiri para pejabat tinggi pemerintah Hindia Belanda. Adapun susunan kabinet Nadjamuddin Daeng Malewa I adalah; Perdana Menteri merangkap Menteri Perekonomian (Nadjamuddin Daeng Malewa), Menteri Uurusan Dalam Negeri (Ide Anak Agung Gde Agung), Menteri Kehakiman (Mr. Tjia Kok Tjiang), Menteri Keuangan (M. Hamelink), Menteri Pendidikan (E. Katoppo), Menteri Penerangan (G. R. Pantouw), Menteri Kesehatan (Dr. S. J. Warrouw), Menteri Pekerjaan Umum dan Perhubungan (E.D. Dengah), dan J. Tahya sebagai Menteri Sosial (Agung, 1985: 181). Prosedur pembentukan kabinet Nadjamuddin itu, mendapat kritikan yang cukup keras dari lawanlawan politiknya, termasuk anggota parlemen NIT. Hal ini merupakan salah satu hambatan bagi kegiatan kabinet yang dipimpinnya. Di samping itu, kedudukan pemerintah Hindia Belanda di Indonesia Timur masih terus berlangsung, yang berarti bahwa Kabinet Nadjamuddin belum memiliki aparat pelaksana pemerintahan. Ini pun menjadi masalah yang sulit, sehingga anggota kabinet ketika berada di Makassar - ibukota NIT, mereka tetap tidak dapat berbuat banyak. Kenyataan itu tidak dapat menepis tanggapan bahwa apa yang dicetuskan di Denpasar hanyalah merupakan boneka buatan Belanda (Kadir, 1984: 217). 


\section{Penataan Pemerintahan NIT}

Sulawesi Selatan adalah salah satu dari tiga belas daerah dalam wilayah Negara Indonesia Timur (NIT). Daerah-daerah lain dalam lingkungan NIT itu adalah; Minahasa, Sangihe dan Kepulauan Talaud, Sulawesi Utara, Sulawesi Tengah, Bali, Lombok, Sumbawa, Flores, Sumba, Timor dan pulau-pulau sekitarnya, Maluku Selatan, dan Maluku Utara. Hal ini sesuai dengan hasil Konferensi Denpasar, yaitu Pasal 14 tentang "Peraturan Pembentukan Negara Indonesia Timur" (Kementerian Penerangan,1953:102-121). Sebelum menjadi bagian dari wilayah NIT, Sulawesi Selatan berdasarkan Keputusan Pemerintah Hindia Belanda tahun 1938 berkedudukan sebagai Residentie Celebes en Onderhoorigheden, yaitu salah satu dari lima keresidenan dalam lingkungan Gouvernement Groote Oost (Pemerintahan Timur Besar). Keresidenan lainnya adalah; Keresidenan Manado, Keresidenan Maluku, Keresidenan Bali dan Lombok, dan Keresiden Timor dan Daerah Takluknya (Staatblad 1938 No. 264). Hampir semua daerah dalam wilayah NIT, kecuali Minahasa dan Maluku Selatan beranggotakan swapraja-swapraja (Zelfbesturende Landschappen). Di Sulawesi Selatan terdapat 30 swapraja (landschap) lama dan 9 swapraja baru (neolandschap) yang diakui sebagai bagian dari Daerah Sulawesi Selatan.

Adapun ketiga puluh swapraja atau kerajaan itu adalah; (1) Gowa, (2) Bone, (3) Luwu, (4) Wajo, (5) Soppeng, (6) Sidenreng, (7) Rappang, (8) Suppa, (9) Sawitto, (10) Mallusetasi, (11) Barru, (12) Tanete,
(13) Soppeng Riaja, (14) Kassa, (15) Batulappa, (16) Alla, (17) Enrekang, (18) Maiwa, (19) Maluwa, (20) Buntu Batu, (21) Majene, (22) Pambuang, (23) Balangnipa, (24) Binuang, (25) Cenrana, (26) Tappalang, Mamuju, (28) Tanah Toraja, (29) Buton, dan (30) Laiwui. Sementara kesembilan swapraja baru itu adalah; (1) Pangkajene, (2) Maros, (3) Takalar, (4) Jeneponto, (5) Bantaeng, (6) Bulukumba, (7) Sinjai, (8) Selayar, dan (9) Mekongga Kolaka. Akan tetapi Swapraja Buton dan Laiwui, serta swapraja baru Mekongga Kolaka, termasuk Sulawesi Tenggara sekarang. Mengenai swapraja-swapraja asli itu, dapat dilihat pada Peraturan Pemerintahan Swapraja tahun 1938, kecuali Swapraja Tanah Toraja (1946). Pembentukan Daerah Sulawesi Selatan tersebut, ditetapkan di Watampone pada tanggal 18 Oktober 1948, dan kemudian disahkan oleh Residen Sulawesi Selatan Dr. J. van Der Zwaal atas nama Pemerintah NIT di Makassar pada tanggal 12 November 1948 (Depdagri, 1991: 189,177 dan 292).

Pada mulanya, pemerintah kolonial Belanda sengaja membiarkan dua pemerintahan berjalan bersamasama dalam NIT, yaitu aparat NIT dan Residen Sulawesi Selatan. Residen masih tetap berfungsi karena Kepala Daerah belum ditunjuk, sehingga ia berfungsi sebagai Kepala Daerah. Sementara dalam struktur NIT sendiri terdiri dari Presiden sebagai Kepala Negara, Perdana Menteri sebagai pimpinan pemerintahan yang memimpin para menteri, Residen, Asisten Residen sebagai pimpinan afdeling, Raja-raja sebagai pimpinan swapraja, Ketua Hadat sebagai 
pimpinan neoswapraja (setingkat dengan onderafdeling/ distrik), dan yang paling bawah adalah kampung atau gabungan kampung. Untuk Kotapraja Makassar, Walikota (Burgemester) setingkat dengan Asisten Residen, namun tidak memiliki aparat setingkat Asisten Residen. Walikota langsung ke distrik (setingkat onderafdeling), kemudian untuk suku bangsa nonbumiputra ditunjuk kapiten/mayor atau kampung/ gabungan kampung/wijk.

Sementara itu, Dewan Selebes Selatan, yang sebelumnya dikenal dengan Dewan Penasehat Sulawesi Selatan atau Dewan Sementara Sulawesi Selatan yang dibentuk pada tanggal 25 Februari 1946, beranggotakan 30 orang (di luar ketua, tiga orang wakil ketua, dan seorang penasehat). Residen Sulawesi Selatan sekaligus Ketua Dewan dan lima anggota dewan ini adalah orang Belanda. Masa tugas dewan ini berakhir 23 Mei 1949, dan digantikan oleh anggota-anggota baru yang dipilih secara langsung. Ketua dewan ketika konferensi pembentukan NIT di Denpasar tahun 1946 adalah Dr. Lion Cachet, kemudian sejak 21 Juli 1948 digantikan oleh Dr. J. van der Swaal (keduanya Residen Sulawesi Selatan), didampingi oleh Wakil-wakil Ketua; Sonda Daeng Mattajang, I. M. Qaimuddin, Abdul Salam, dan Penasehat dewan M. Sjafei. Anggotaanggotanya antara lain adalah; Abdoel Havid, Theong Hong Tjing, P. H. Kramer, H. L. Lete, Hamelink, Leyssius, van Emstede, Ir. Diapari, Andi Gappa, Sangkala Daeng Palili, A. Massarappi, Andi Ronda, Marzoeki Daeng Marala, Abdoel Razak, Laode Miki, S. Hasan bin Achmad Alamoedi,
Lasandara, La Djere Daeng Marala, Nassa, Andi Iskandar, M. Akib, Bangsawan Daeng Lira, Malandjong Daeng Liwang, A. M. Tahir, A. Mappangara, A. Boerhanuddin, H. Sewang Daeng Moentoe, Baoesat Daeng Sitaba, A. Pallawaroekka, dan Andi Idjo. Delapan orang di antara mereka ini mewakili Dewan Selebes Selatan ke Konferensi Denpasar. Dewan ini bersidang untuk mendengarkan langsung hasil Konferensi Denpasar dari Perdana Menteri Nadjamuddin Daeng Malewa pada tanggal 10-12 Februari 1947. Tampil memberikan tanggapan dalam sidang ini antara lain; Sonda Daeng Mattajang dan S. Hasan bin Achmad Alamoedi. Hampir semua mereka dapat menerima hasil Konferensi Denpasar (Arsip Tator, No. 82).

$$
\text { Mengenai penataan }
$$

pemerintahan dalam negeri sesuai dengan hasil Konferensi Denpasar, Pasal 5 Peraturan Pembentukan NIT, antara lain disebutkan bahwa negara berkewajiban memperhatikan kedudukan istimewa daerah-daerah swapraja. Kebijakan lebih lanjut mengenai hal itu disampaikan oleh Presiden NIT Soekawati dan Perdana Menteri Nadjamuddin pada sidang parlemen tanggal 22 April 1947. Kemudian dipertegas lagi oleh Menteri Urusan Dalam Negeri, Ide Anak Agung Gde Agung pada sidang parlemen tanggal 28 April 1947. Para pejabat NIT itu menyinggung pentingnya kedudukan swapraja dalam NIT dan menekankan perlunya modernisasi dan demokratisasi pemerintahan kerajaan. Menurutnya, demokratisasi pemerintahan kerajaan berarti menempatkan orang-orang yang mampu yang mungkin tidak sesuai 
dengan tingkatan aristokratnya untuk melakukan pemerintahan kerajaan. Kalau rakyat merasa terwakili dalam pemerintahan, maka rakyat akan melihat pemerintah kerajaan sebagai bapak dan penghulu dari rakyat (Agung, 1985: 191-221).

Pada masa Anak Agung menjadi Perdana Menteri NIT, penataan struktur kenegaraan yang sudah dicanangkan sewaktu menjadi Menteri Urusan Dalam Negeri dalam Kabinet Nadjamuddin dan Warrouw diteruskan. Pola penentuan daerah yang sudah diucapkannya setahun sebelumnya direalisasikan. Umpamanya Sulawesi Selatan sebagai satu daerah merupakan gabungan dari semua swapraja lama ditambah dengan daerah-daerah yang dulu diperintah secara langsung, yang kemudian dibentuk swapraja-swapraja baru atau yang dikenal sebagai neolandschap. Pola semacam ini berlaku untuk semua daerah-daerah lainnya di NIT. Bagi swapraja yang belum memiliki dasar hukum, maka dibuatkan surat keputusan baru, misalnya Swapraja Tanah Toraja (24 Juli 1947), Hadat Bulu-kumba, Selayar, dan Jeneponto (4 Juni 1948), dan lainlain (Depdagri, 1991: 277).

Rancangan tentang pembentukan Gabungan Sulawesi Selatan dan Dewan Selebes Selatan sudah dirampungkan pada bulan September1947. Kemudian Residen Sulawesi Selatan mengundang para raja dan pimpinan hadat untuk mengadakan pertemuan di Sengkang pada tanggal 12 April 1948. Dalam pertemuan itu mereka bersepakat membentuk Gabungan Sulawesi Selatan, dengan Hadat Tinggi sebagai eksekutifnya, dan Dewan Selebes Selatan sebagai badan legislatif.
Ditekankan bahwa Hadat Tinggi tidak akan mencampuri fungsi Dewan Selebes Selatan dalam proses mempersiapkan undang-undang, penetapan anggaran, dan lain sebagainya. Pada pertemuan di Sengkang itu, juga Raja Bone Andi Pabbenteng mengusulkan setiap swapraja (lama dan baru) duduk dalam Gabungan Sulawesi Selatan, namun jumlah jatah/ wakil swapraja dalam Hadat Tinggi ditentukan menurut jumlah penduduk di setiap afdeling, yaitu Afdeling Bone diusulkan tiga wakil, sementara Afdeling Luwu, Makassar, Parepare, Bantaeng, Mandar, dan Buton/ Laiwui masing-masing dua orang wakil, sehingga seluruhnya berjumlah 15 orang (Arsip Tator, No.72). Hasil pertemuan Sengkang ini dibicarakan dalam rapat Dewan Selebes Selatan (yang lama, Dewan Penasehat Sulawesi Selatan) pada tanggal 27 April 1948. Karena sebagian dari anggota dewan ini adalah para pimpinan swapraja, sehingga keputusan yang telah diambil itu dapat diterima oleh Dewan Selebes Selatan.

Pembentukan

Gabungan

Sulawesi Selatan yang terdiri atas 30 swapraja lama dan 9 swapraja baru ditetapkan di Watampone pada tanggal 18 Oktober 1948, dan kemudian disahkan oleh Pemerintah NIT pada tanggal 12 November 1948. Hadat Tinggi yang merupakan badan pekerja harian Gabungan Sulawesi Selatan berfungsi sebagai eksekutif dengan masa kerja empat tahun dan sesudah itu dapat dipilih kembali. Ketua Hadat Tinggi merupakan penguasa baru yang menggantikan kedudukan Residen Sulawesi Selatan. Ia didampingi oleh seorang Ketua Muda dan 13 anggota 
lainnya. Jadi jumlahnya 15 orang, sesuai dengan keputusan yang pernah diambil dalam pertemuan di Sengkang tanggal 21 April, yang kemudian dimantapkan dalam pertemuan di Watampone tanggal 18 Oktober 1948. Terpilih menjadi Ketua Hadat Tinggi (Raja Bone Andi Pabbenteng), Ketua Muda (Raja Gowa Andi Idjo Karaeng Lalolang), dengan anggota-anggota; Andi Singke, Andi Mappatoba, Andi Tjalla, Andi Mangkona, Abdoelgani, Andi Tjalo, Andi Moh. Tahir, Kamba, La Magga, Andi Borahima, Andi Lolo, Sultan Buton, dan Sapati Kendari. Mereka dilantik oleh pemerintah NIT dengan pesta kebesaran berupa parade berkuda dari Kerajaan Gowa pada tanggal 12 November 1948. (Arsip Tator, No.72; Arsip NIT, No.3/c).

Selain penataan pemerintahan dalam negeri tersebut, Kabinet Anak Agung juga sungguh-sungguh menjalankan politik perpaduannya (sintesa) terhadap Republik Indonesia dan merangkul semua negara-negara dan daerah-daerah di luar NIT untuk mengusahakan agar secepatnya terwujud Negara Indonesia Serikat yang merdeka dan berdaulat. Itulah sebabnya ketika Belanda melancarkan Agresi Militer II terhadap Republik Indonesia pada tanggal 19 Desember 1948, Kabinet Anak Agung meletakkan jabatan dan mengembalikan mandat kepada Presiden NIT pada hari itu juga. Presiden Soekawati tidak bisa berbuat lain kecuali menerima pengunduran diri Kabinet Anak Agung. Namun Presiden NIT kembali meminta Anak Agung untuk membentuk kabinet yang baru. Kabinet Anak Agung II diumumkan pada tanggal 12 Januari 1949.
Sebagian besar para menteri yang duduk dalam Kabinet Anak Agung II tersebut masih muka-muka lama, kecuali Menteri Kesehatann Dr. J. W. Grootings yang menggantikan Dr. S. J. Warrouw. Selain itu kabinet ini lebih ramping dari kabinet sebelumnya. Adapun susunan kabinet ini adalah sebagai berikut; Perdana Menteri merangkap Menteri Urusan Dalam Negeri (Ide Anak Agung Gde Agung), Menteri Kehakiman (Dr. Mr. Ch. R. S. Soumokil), Menteri Perekonomian (Drs. Tan Tek Heng), Menteri Keuangan (M. Hamelink), Menteri Pendidikan (J.E. Tatengkeng), Menteri Sosial (Mr. S. Binol), Menteri Kesehatan (Dr. J. W. Grootings), Menteri Pekerjaan Umum dan Perhubungan (Ir. D. P. Diapari), dan Menteri Penerangan (I. H. Doko). Pada tanggal 12 Maret 1949 Abdul Rajab Daeng Massikki diangkat sebagai Menteri Perekonomian dan semenjak itu Drs. Tan Tek Heng bertindak sebagai Menteri Negara (Agung, 1985:483). Kegiatan Kabinet Anak Agung II ini lebih diarahkan untuk mengembangkan kerjasama antara sesama negara-negara bagian dan daerah-daerah "ciptaan Van Mook". Kerjasama mereka itu kemudian dikenal dengan Pertemuan Musyawarah Federal (Bijeenkomst Federasi Overleg, disingkat $B F O$ ), yang bertujuan untuk mempercepat terwujudnya Negara Indonesia Serikat. Upaya-upaya itu akhirnya melapangkan terlaksananya pertemuan Inter Indonesia, yaitu antara negara-negara anggota $B F O$ dan Republik Indonesia di Yogyakarta (19-22 Juli) dan di Jakarta (31 Juli-2 Agustus 1949). Hasil pertemuan Inter Indonesia itu kemudian menjadi patokan pemikiran 
bagi utusan dan wakil-wakil Indonesia dalam Konferensi Meja Bundar (KMB). Dengan demikian menjelang berlangsunnya $\mathrm{KMB}$, telah tercipta perpaduan (sintesa) pendapat antara negara-negara bagian "ciptaan" Belanda dengan Republik Indonesia untuk mewujudkan Negara Indonesia Serikat yang merdeka dan berdaulat (Kadir, 1984: 228-230; Agung, 1985: 493-595).

Pada masa Kabinet Anak Agung II ini pula, penataan pemerintahan dalam negeri yang telah dicanangkan sebelumnya tetap dilanjutkan. Umpamanya pembentukan Senat NIT, yaitu terdiri atas seorang ketua dan 13 anggota yang merupakan wakil yang sudah pilih dari setiap daerah dalam lingkungan NIT. Presiden NIT melantik secara resmi Senat NIT pada tanggal 28 Mei 1949. Adapun anggota Senat NIT itu adalah: W. A. Sarapil (Sangihe dan Talaud), M. P. Tangkilisang (Minahasa), H. J. C. Manoppo (Sulawesi Utara), Soamir Raja Banggai (Sulawesi Tengah), Andi Sumangarukka (Sulawesi Selatan), Sultan Iskandar Moh. Syah (Maluku Utara), Ir. J. A. Manusama (Maluku Selatan), Alfons Nisnoni (Timor), Bapa Kaya (Flores), Oemboe Toenggoe Billi (Sumba), Laloe Madjakawang (Sumbawa), Haji Hasyim (Lombok), dan I Gusti Ngurah Kante (Bali). Oleh karena W. A. Sarapil terpilih menjadi Ketua Senat, maka daerah SangiheTalaud berhak menunjuk lagi seorang anggota untuk menggantikan W. A. Sarapil. Wewenang Senat terletak pada perundang-undangan dan memberi nasihat kepada pemerintah. Karena itu semua penyusunan perundangundangan atau peraturan-peraturan
Presiden/ Pemerintah diwajibkan mendengar pendapat Senat. Walaupun Senat tidak berhak untuk menolak atau mengubah suatu rancangan undangundang atau peraturan Presiden, tetapi mempunyai wewenang untuk menahan rancangan yang diajukan itu dan mengembalikan lagi kepada pemerintah. Dalam segala hal yang menyangkut pemerintahan umum, Pemerintah dapat meminta nasihat Senat, tetapi dalam hal-hal yang menyangkut persoalan daerah, khususnya mengenai swapraja Pemerintah diwajibkan mendengar nasihat Senat (Agung, 1985: 457 dan 588).

Setiap peraturan yang dikeluarkan oleh pemerintah NIT, harus mendapat persetujuan dari Badan Perwakilan Rakyat dan Senat. Dengan demikian Senat bersama Badan Perwakilan Rakyat merupakan Parlemen NIT. Selain itu, pemerintah NIT juga membentuk tiga Komisaris Negara, yaitu Utara, Tengah, dan Selatan pada bulan Agustus 1949. Komisaris Negara Utara berkedudukan di Manado, meliputi daerah-daerah Minahasa, Sulawesi Utara, SangiheTalaud, Sulawesi Tengah, dan Maluku Utara. Komisaris Negara Tengah berkedudukan di Makassar, meliputi daerah Sulawesi Selatan dan Maluku Selatan. Komisaris Negara Selatan berkedudukan di Singaraja, meliputi daerah Bali, Lombok, Sumba, Sumbawa, Flores, Timor dan daerahdaerah sekitarnya. Untuk Komisaris Negara Utara diangkat J. Gerungan dan Komisaris Negara Selatan diangkat Mr. Anak Agung Ngurah Ketut Djelantik (Arsip NIT, No.1 dan 12). Namun pembentukan Komisaris Negara, 
khususnya untuk Komisaris Negara Tengah tidak disetujui oleh Hadat Tinggi Sulawesi Selatan. Mereka berpendapat bahwa kedudukan dan kehormatannya akan dikurangi karena harus memperhatikan petunjuk Komisaris Negara yang bersangkutan, sekalipun kedudukannya hanya sebagai pejabat untuk mengawasi dan membantu pemerintah daerah. Itulah sebabnya Komisaris Negara Tengah belum diangkat hingga bulan Desember 1949 (Agung, 1985: 673).

Hadat Tinggi yang merupakan badan pekerja harian Gabungan Sulawesi Selatan berfungsi sebagai badan eksekutif dan didampingi oleh Dewan Selebes Selatan yang berfungsi sebagai badan legislatif. Sebelum Dewan Selebes Selatan yang baru terbentuk melalui pemilihan umum, Dewan Penasehat Sulawesi Selatan yang dulu dibentuk pada tanggal 25 Februari 1946, masih tetap berfungsi hingga akhir masa tugas (23 Mei 1949) dan digantikan oleh anggota-anggota yang baru terpilih. Pemilihan anggota Dewan Selebes Selatan yang baru selesai dilaksanakan pada tanggal 21 April 1949. Dewan ini dipimpin oleh Andi Burhanuddin (mantan Karaeng Pangkajene dan mantan tokoh PNI) yang pro Republik. Seperti halnya dalam Badan Perwakilan Sementara NIT, tidak sedikit anggota-anggota Dewan Selebes Selatan yang pro Republik, termasuk ketuanya sendiri. Dalam sidang Dewan Selebes Selatan ditetapkan bahwa pembicaraan dalam dewan harus memakai bahasa Indonesia. Kalau ada anggota yang memakai bahasa lain, ketua harus menjelaskan isinya kepada rapat dalam bahasa Indonesia (Arsip Tator, No. 83).

\section{Kembali Ke Negara Kesatuan RI}

Pertemuan antara wakil-wakil dari Republik Indonesia, negaranegara/daerah bagian yang diorganisir dalam Pertemuan Musyawarah Federal (Bijeenkomst Federaal Overleg, disingkat $B F O$ ) dengan pemerintah Belanda yang berlangsung di Den Haag - Negeri Belanda dari tanggal 23 Agustus sampai dengan 2 November 1949. Hasil terpenting dari KMB itu adalah pemerintah Belanda akan "menyerahkan" kedaulatan sepenuhnya atas wilayah Indonesia (Hindia Belanda) kepada pemerintah Republik Indonesia Serikat (RIS) dengan tidak bersyarat selambat-lambatnya pada tanggal 30 Desember 1949. Realisasi dari rencana itu ternyata terjadi tiga hari sebelum jangka waktu yang ditetapkan, yaitu pada tanggal 27 Desember 1949. Penyerahan kedaulatan tanpa syarat itu, mengandung arti bahwa tidak ada larangan adanya perubahan bentuk dan struktur ketatanegaraan di kemudian hari (Harvey, 1989: 153).

Selama berlangsunya KMB, pemerintah Belanda membebaskan sekitar 12.000 orang tahanan antara bulan Agustus sampai dengan Desember 1949. ${ }^{1}$ Mereka yang ditahan itu, bukan

1 Tampaknya jumlah tahanan berbeda antara Republik dan pihak Belanda. Pihak republik mengatakan jumlah tawanan diperkirakan 14.500 orang. Wakil Mahkota Belanda memberikan keterangan sejak berlakunya penghentian tembak menembak sampai dengan 13 Desember 1949 telah diberikan amnesti sebanyak 3.194 orang. Pihak Republik menyampaikan daftar orang yang dibebaskan sejak 10 Agustus sampai dengan 16 Desember1949 adalah sebanyak 7.862 orang, daftar itu menjadi bertambah sejak periode 28 Desember 1949 sampai 1 Maret 1950 sebanyak 4.414 orang. Menteri Kehakiman RIS Mr. Soepomo 
saja karena berjuang mempertahankan proklamasi kemerdekaan, tetapi juga karena mereka menentang pemerintah Belanda yang hendak memulihkan kembali pengaruh dan kedudukan kekuasaan kolonialnya di Indonesia. Meskipun demikian, di Sulawesi Selatan salah seorang pemuda pejuang kemerdekaan Indonesia, yaitu Robet Wolter Mongisidi harus menerima hukuman mati di hadapan regu tembak pada tanggal 5 September 1949. Sementara para tahanan lainnya yang dipenjarakan di Kota Makassar dan kota-kota lain di Sulawesi Selatan serta di luar wilayah Sulawesi Selatan juga dibebaskan, misalnya mantan Raja Bone Andi Mappanyukki yang diasingkan Belanda ke Tana Toraja, mantan Datu Luwu Andi Djemma diasingkan ke Ternate, Dr. Ratulangi dan Staf Gubernur Sulawesi diasingkan ke Serui (Irian Jaya), Karaeng Polombangkeng Padjongan Daeng Ngalle dan Andi Depu dipenjarakan di Makassar, dan lain-lain. Para tahanan yang dipenjarakan di Kota Makassar (Hogepad, Lajang, dan Tellokamp) jumlahnya diperkiran lebih dari 500 orang, di Bulukumba berjumlah 762 orang dan 618 orang di antaranya dibebaskan pada awal Januari 1948. Di

menyampaikan dalam sidang Parlemen RIS tangal 11 Maret 1950, bahwa dari tanggal 10 Agustus-27 Desember 1949, pemerintah Belanda membebaskan sebanyak 7.862 tahanan, sebagian besar belum diadili. Dari 4 November27 Desember 1949 sebanyak 4.589 tahanan yang sudah dalam kategori tersangka, dan dari 27 Desember 1949-awal Maret 1950 dibebaskan sebanyak 4.414 orang tahanan sebagai narapidana amnesti. Baca "Pernyataan Menteri Kehakiman Soepomo, Pertanyaan anggota parlemen dan jawaban pemerintah, 11 Maret 1950, hlm. 61-67 (Chaniago, 2002: 577).
Jawa lebih dari 300 orang pejuang/TRI Sulawesi Selatan yang ditahan di penjara Nusakambangan. Mereka kemudian diurus oleh Panitia Penerimaan Bekas Tawanan yang dibentuk sejak akhir 1949, dan panitia ini melaporkan telah menampung sebanyak 1.410 orang tawanan, dan sebagian dibantu mengembalikan ke Sulawesi Selatan. Sebagian dari para tahanan itu adalah para raja atau keluarga kerajaan yang anti Belanda (Arsip Bantaeng, No. 82; Arsip NIT, No.141 dan 142).

Berdasarkan hasil KMB antara lain dinyatakan bahwa sehubungan dengan penyerahan kedaulatan, maka penjagaan keamanan Indonesia menjadi tanggungjawab RIS. Koninklijke Marine (KM) atau Angkatan Laut Belanda, Koninklijke Landmacht $(K L)$ atau Angkatan Darat Belanda, dan Koninklijke Luchwacht atau Angkatan Udara Belanda akan ditarik. Sedang Koninklijke Nederlands Indsche Leger $(K N I L)$ akan diatur tersendiri pengorganisasiannya ke dalam APRIS (Chaniago, 2002: 380). Berpedoman pada hasil KMB dan penyerahan kedaulatan itu, pemerintah RIS dalam hal ini Menteri Pertahanan merencanakan untuk menempatkan seorang perwira TNI di seluruh negara/ daerah bagian RIS untuk menjadi Gubernur Militer yang akan menerima tanggungjawab wilayah dari Tentara Belanda, dan selanjutnya menyerahkan kepada penguasa sipil RIS. Untuk itu, Menteri Pertahanan bersama Kepala Stafnya, Kolonel A.H. Nasution mengadakan perjalanan ke seluruh ibukota negara/daerah bagian RIS. Pada tanggal 23 Desember 1949, Menteri Pertahanan RIS sampai di Makassar. Setelah be- 
runding selama dua hari, tampaknya tidak ada kesepakatan mengenai penempatan Gubernur Militer dan pasukan TNI di NIT. Dalam pengumuman yang ditandatangani bersama (Menteri Pertahanan dan Presiden NIT Soekawati), antara lain disebutkan bahwa; 1) oleh karena keadaan perang tidak ada lagi di NIT, maka tidak akan ditempatkan seorang Gubernur Militer; 2) ketertiban umum menjadi tanggungjawab pemerintah NIT, dan bila perlu APRIS dapat memberi bantuan; 3) selain pemerintah tidak diperkenankan mendirikan organisasi kemiliteran atau para militer; dan 4) akan dibentuk suatu Komisi Militer Teritorial untuk wilayah NIT yang berkedudukan di Makassar, karena belum ada APRIS di NIT (Agung, 1985: 687; Harvey, 1989: 155).

Rencana penempatan Gubernur Militer dan pasukan TNI di dalam NIT tidak diterima pemerintah NIT, sehingga tugas itu dialihkan kepada sebuah komisi yang dibentuk dengan sebutan "Komisi Militer dan Teritorial Indonesia Timur" (KMTIT). Komisi ini diketuai oleh Ir. Putuhena dengan didampingi seorang anggota dari TNI, Letkol A. J. Mokoginta, dan seorang anggota dari KNIL, Mayor Nanhohy, serta dilengkapi dengan staf. Namun Menteri Pertahanan menekankan bahwa pemindahan tanggungjawab militer dari pihak Belanda harus diserahkan kepada perwira TNI. Itulah sebabnya Letkol A. J. Mokoginta yang menyertai kedatangan Menteri Pertahanan, tetap berada di Makassar untuk menerima pengalihan tanggungjawab teritorial militer untuk Indonesia Timur dari Kolonel Schotborgh (Komandan KNIL) ketika upacara penyerahan kedaulatan dilakukan pada tanggal 27 Desember 1949 (Arsip Saleh Lahade, No.152; Chaniago, 2002: 409; Harvey, 1989: 156).

Penyerahan kedaulatan kepada RIS oleh pemerintah Belanda tersebut, tampaknya akan menimbulkan masalah baru dan mendapat tanggapan yang berbeda di NIT. Bagi sebagian elite politik pro federasi, kehadiran RIS dirasakan sebagai suatu kemenangan politik. Adanya RIS berarti dengan mudah menyingkirkan orang Belanda dalam pemerintahan. Selain itu, adanya RIS menaikkan prestise NIT di mata Republik, antara lain karena strategi perjuangan tanpa revolusi yang dicanangkan sebelumnya dalam pandangan mereka lebih ampuh daripada revolusi yang dilaksanakan Republik Indonesia. Demikian pula bagi sebagian aristokrat yang dulu pro Belanda, dan termasuk elite politik pro federasi, kehadiran RIS merupakan harapan masa depan yang lebih cerah. Sebaliknya bagi para pejuang pro Republik, yaitu para gerilyawan, mantan tahanan politik/ perang yang dipenjarakan Belanda, elite politik pro Republik yang berada dalam pemerintahan dan parlemen NIT, para pejuang/TNI Sulawesi Selatan yang kembali dari Jawa, kehadiran RIS hanyalah dianggap sebagai suatu batu loncatan menuju kepada negara kesatuan Republik Indonesia (Kementerian Penerangan, 1953:152; Chaniago, 2002: 568). Itulah sebabnya setelah penyerahan kedaulatan, para pejuang kemerdekaan Indonesia tetap berusaha untuk mewujudkan Negara Kesatuan Republik Indonesia.

Gambaran tentang penyerahan kedaulatan tidak memberikan kepuasan kepada rakyat dan para pejuang 
kemerdekaan Indonesia di Sulawesi Selatan, tercermin dalam resolusi, mosi, desakan, dan sebagainya yang dikeluarkan oleh berbagai organisasi sosial atau politik. Kenyataan itulah yang mendasari para pejuang menyelenggarakan rapat akbar untuk merumuskan kembali keinginan yang telah mendasari perjuangannya. Dalam rapat akbar yang diselenggarakan di Polombangkeng tanggal 5-7 Februari 1950, berhasil disepakati pembentukan Biro Pejuang Pengikut Republik Indonesia (BPPRI). Selain itu, juga dicapai kesepakatan untuk menuntut pembubaran NIT dan RIS serta mendesak pemerintah untuk mewujudkan kembali negara kesatuan Republik Indonesia (Arsip A.R. Tamma, No.12; Djarwadi, 1972: 45). Untuk merealisasikan perjuangan itu, diutuslah Makkaraeng Daeng Mandjarungi dan M. Riri Amin Daud sebagai wakil BPPRI ke Yogyakarta pada tanggal 23 Februari 1950, untuk menyampaikan sikap para pejuang di Sulawesi Selatan kepada pemerintah RIS dan Republik Indonesia, yang pada intinya menghendaki RIS dibubarkan dan kembali kepada negara kesatuan Republik Indonesia. Selain itu, tokohtokoh BPPRI lainnya juga bergiat mengorganisir partai-partai politik dan organisasi perjuangan untuk berjuang membubarkan NIT dan RIS. Usahausaha itu akhirnya mendorong GAPKI (Gabungan Pejuang Kemerdekaan Republik Indonesia) menyelenggarakan pertemuan dengan organisasi perjuangan lainnya pada tanggal 16 Maret 1950. Dalam pertemuan itu berhasil dicapai kesepakatan untuk melaksanakan demonstrasi besar-besaran menuntut pembubaran NIT dan RIS pada tanggal 17 Maret 1950 (Arsip NIT, No.129; Kementerian Penerangan, 1953: 162). Maraknya tuntutan agar NIT dibubarkan mengakibatkan suhu politik makin meningkat di Sulawesi Selatan, yang sebagian juga dipengaruhi oleh peristiwa-peristiwa yang terjadi di luar wilayah NIT. ${ }^{2}$ Pergolakan-pergolakan

${ }^{2}$ Misalnya Gerakan APRA Westerling yang melancarkan serangan terhadap APRIS di Bandung pada tanggal 23 Januari 1950. Walaupun tidak dapat dibuktikan keterlibatan pemerintah Pasundan dalam peristiwa itu, tetapi parlemen Negara Pasundan mengajukan pertanyaan tidak percaya kepada pemerintah yang bermuara pada berhentinya kabinet dan mundurnya Wali Pasundan. Akibatnya timbul kekeruhan politik yang luar biasa, sehingga pemerintah mengangkat seorang Komisaris di negara itu di bawah Pemerintah Federal (Pusat) dan Negara Pasundan dalam proses pembubaran. Kejadian di Pasundan menimbulkan reaksi berantai di Negara Jawa Tengah, Jawa Timur, dan Negara Madura. Untuk menghindari terjadinya krisis politik yang lebih hebat, Pemerintah Pusat di Jakarta mengambil kebijakan yang sama dengan di Negara Pasundan. Ketiga negara/daerah itu masing-masing diangkat seorang Komisaris di bawah Pemerintah Federal. Kemudian menyusul Negara Sumatra Selatan akibat terjadinya ketegangan politik di sana, sehingga Pemerintah Federal pun bertindak sama. Pergolakanpergolakan politik yang terjadi di negara/daerah bagian itu disebabkan pertentangan antara golongan unitaris dan federalis dan terjadinya demonstrasi secara besar-besaran yang menuntut agar negara kesatuan diwujudkan kembali. Untuk mengatasi masalah tersebut, maka keluarlah undang-undang darurat yang disetujui BPRS RIS pada tanggal 8 Maret 1950, dengan mengakses melalui pasal 139 UUD RIS, yang menyebutkan; 1) Pemerintah berhak atas kuasa dan tanggung sendiri menetapkan undangundang darurat yang mengatur hal-hal penyelenggaraan pemerin-tahan federal yang karena keadaan yang mendesak perlu diatur dengan segera; 2) Undang-undang darurat mempunyai kekuasaan dan kuasa undangundang federal, ketentuan ini tidak mengurangi yang ditetapkan dalam pasal berikutnya 
politik di Jawa, Madura, Sumatra, dan lainnya yang berkisar pada masalah pertentangan antara kelompok unitaris dan federalis, dan hasrat untuk mengukuhkan kembali negara kesatuan Republik Indonesia. Pergolakan yang sama juga terjadi di NIT terutama di Makassar, bahkan tampaknya sudah tidak terkendali lagi sehingga akan membahayakan keamanan dan ketertiban umum. Itulah sebabnya untuk meredakan suasana dan menghindari terjadinya bentrokan fisik antargolongan, Kabinet Tatengkeng mengeluarkan keputusan melarang demonstrasi oleh semua pihak dan golongan, dengan penjelasan bahwa masalah penentuan asas federasi atau kesatuan (unitaris) harus diputuskan melalui saluran yang demokratis, yaitu melalui Badan Perwakilan Rakyat atau plebisit. Keputusan Kabinet Tatengkeng itu ditentang dengan keras oleh kelompok unitaris (Agung, 1985: 704).

Maraknya tuntutan agar NIT dibubarkan dan digabungkan dengan Republik Indonesia, mengundang pula perhatian dari kalangan aristokrat atau bangsawan di Sulawesi Selatan, yang pro Republik dan tidak ingin memperoleh kedaulatan dalam bentuk negara federasi. Tampaknya mereka berusaha atau lewat pemerintah Republik Indonesia yang berada di Yogyakarta agar membubarkan RIS

(Chaniago,2002:386). Dampak dari undangundang darurat tentang pembubaran negara/ daerah bagian dan penyatuannya ke dalam Republik Indonesia, memang ampuh karena hingga akhir Maret 1950 tinggal Kalimantan Barat, Sumatra Timur, NIT yang belum bergabung ke dalam Republik Indonesia (Harvey, 1989: 164; Agung, 1985: 700-704). dan melalui Hadat Tinggi Sulawesi Selatan dan Dewan Selebes Selatan untuk membubarkan NIT. Untuk mewujudkan maksud itu maka diberangkatkan sejumlah pimpinan dari kalangan aristokrat atau bangsawan yang pro Republik dan berpendirian unitaris ke Yogyakarta pada akhir Maret 1950. Mereka itu antara lain Andi Mappanyukki (mantan Raja Bone), Datu Luwu Andi Djemma, Karaeng Polombangkeng Padjonga Daeng Ngalle, dan Karaeng Gattarang Andi Sultan Daeng Radja. Rombongan itu di bawah pimpinan Lanto Daeng Pasewang dan disertai oleh Kapten M. Jusuf dan Letnan Bing Latumahina dari KMTIT (Harvey, 1989: 161; Kadir, 1984: 244). Hal inilah yang mendasari penyataan Pemerintah Daerah Sulawesi Selatan dan Dewan Selebes Selatan, yang masing-masing diwakili oleh Andi Idjo Karaeng Lalolang (Wakil Ketua Hadat Tinggi Sulawesi Selatan) dan Andi Burhanuddin (Ketua Dewan Selebes Selatan), bahwa:

"Sesuai dengan kehendak sebagian besar rakyat Sulawesi Selatan yang diwujudkan dalam bentuk demonstrasi, mosi, dan pernyataan pada rapat umum tanggal 20 Maret 1950 yang diselenggarakan oleh Panitia Penegak Republik Indonesia yang meliputi lebih dari 50 partai politik dan organisasi masyarakat, maka mulai tanggal 26 April 1950, Pemerintah Daerah Sulawesi Selatan dan Dewan Selebes Selatan menyatakan bahwa Sulawesi Selatan melepaskan diri dari Negara Indonesia Timur dan masuk dalam Republik Indonesia 
sebagai satu propinsi. Kepada Pemerintah Republik Indonesia Serikat dan Pemerintah Republik Indonesia kami mendesak, agar supaya pernyataan kami dengan selekasnya disahkan"(Depdagri, 1991: 306 - 307; Kementerian Penerangan, 1953:169).

Proklamasi Sulawesi Selatan lepas dari NIT dan menjadi provinsi Republik Indonesia tidak dapat terealisasi. Hal ini bukan saja disebabkan karena kebijakan dari Perdana Menteri RIS Mohammad Hatta, yang menggariskan bahwa aspirasi dan kehendak rakyat harus disalurkan secara demokratis dan bisa dipertanggungjawabkan secara hukum, yang disebut dengan "legal konstitusonal demokratis". Ini artinya harus melalui lembaga-lembaga kenegaraan seperti DPR-Senat RIS, dan Keputusan Presiden RIS. Akan tetapi juga karena sebelum Proklamasi Sulawesi Selatan tanggal 26 April itu, telah berlangsung Konferensi Segi Tiga antara RIS, NIT, dan RI pada tanggal 10 April 1950, yang menghasilkan antara lain bahwa:

a. Pembicaraan diadakan dalam suasana ramah tamah dan hati terbuka.

b. Ketiga pihak berpendapat bahwa soal-soal yang mengenai Negara Indonesia Timur dengan timbulnya kesukaran pada waktu sekarang, harus diselesaikan atas dasar persatuan bangsa Indonesia yang sekokoh-kokohnya.

c. Dari pihak negara RI nyata tidak ada niat untuk meleburkan sesuatu daerah ke dalam lingkungan kekuasaannya, melainkan segala se- suatu diserahkan kepada keinginan rakyat.

d. Dari pihak Negara Indonesia Timur dinyatakan bahwa rakyatlah yang akan menentukan secara konstitusional dan demokratis bentuk ketatanegaraan Indonesia di kemudian hari (Agung, 1985: 733; Chaniago, 2002: 668).

Pada hari itu Perdana Menteri RIS Mohammad Hatta berpidato bahwa yang paling penting dan utama adalah persatuan bangsa yang harus dipelihara dan segala pertentangan politik harus diselesaikan secara demokratis dan tidak dengan jalan teror atau kekerasan. Konferensi itu tentu berkaitan dengan makin meningkatnya tuntutan untuk bergabung kembali dengan Republik Indonesia, dan munculnya keinginan untuk mengubah bentuk negara federal (RIS) menjadi negara kesatuan (Agung,1985:734). Usaha-usaha itu akhirnya melapangkan jalan bagi terbentuknya Negara Kesatuan Republik Indonesia berdasarkan Proklamasi Kemerdekaan Republik Indonesia 1945. Presiden Republik Indonesia, Ir. Soekarno, dalam pidato kenegaraannya dalam rangka menyambut peringatan Proklamasi Kemerdekaan Republik Indonesia yang kelima, tanggal 17 Agustus 1950, mengumumkan pembubaran RIS dan menyatakan kembali kepada Negara Kesatuan Republik Indonesia. Dengan demikian Sulawesi Selatan menjadi bagian dari negara kesatuan itu, sesuai tuntutan sebagian besar rakyatnya. Akan tetapi statusnya tidak menjadi daerah otonom dengan provinsi tersendiri sebagaimana yang dikehendaki oleh rakyatnya, melainkan 
hanyalah bagian dari Provinsi Sulawesi.

\section{PENUTUP}

Pembentukan Negara Indonesia Timur (NIT) tidak terlepas dari berbagai peristiwa konflik kepentingan, dan keinginan untuk menyelenggarakan pemerintahan secara otonom. Proses pembentukannya pun didasarkan realitas politik saat itu, sehingga mampu menjadi negara federal yang paling berkembang dan otonom di antara negara-negara federal lainnya. Namun keinginan sebagai masyarakat untuk tetap mempertahankan eksistensi negara federal NIT, telah kalah bersaing oleh deraan gelombang semangat unitaris menuju Negara Kesatuan Republik Indonesia. Proses runtuhnya Negara Indonesia Timur dan tegaknya negara kesatuan di Sulawesi Selatan telah menunjukkan terjadinya proses keIndonesiaan.

\section{DAFTAR PUSTAKA}

Agung, Anak Agung Gde. 1985.

Dari Negara Indonesia Timur ke Negara Republik Indonesia Serikat. Yogyakarta: Gadjah Mada University Press.

Agung, Anak Agung Gde. 1992.

Negara Kesatuan: Negara Indonesia Timur. Makalah Seminar Sejarah Regional Indonesia Timur.

Arsip A. R. Tamma, No. 12. Koleksi Badan Arsip dan Perpustakaan Propinsi Sulawesi Selatan.

Arsip Bantaeng, No. 82. Koleksi Badan Arsip dan Perpustakaan Propinsi Sulawesi Selatan.
Arsip Negara Indonesia Timr (NIT), No. 1, 3/c, 12, 129, 141, dan 142. Koleksi Badan Arsip dan Perpustakaan Propinsi Sulawesi Selatan.

Arsip Saleh Lahade, No.152. Koleksi Badan Arsip dan Perpustakaan Propinsi Sulawesi Selatan.

Arsip Tator, No. 72, 82, dan 83. Koleksi Badan Arsip dan Perpustakaan Propinsi Sulawesi Selatan.

Budiardjo, Miriam,1986. Dasar-Dasar Ilmu Politik. Jakarta: Gramedia.

Chaniago, J. R., 2002.

Revolusi, Politik Lokal dan Integrasi Nasional Pengalaman Sulawesi Selatan dan Sumatra Timur Memasuki Negara Kesatuan Republik Indonesia 1950. Disertasi, Yogyakarta: Universitas Gadjah Mada.

Depdagri, 1991. Sejarah Perkembangan Pemerintahan Departemen dalam Negeri di Propinsi Daerah Tingkat I Sulawesi Selatan. Ujung Pandang: Penda Tk. I Sulawesi Selatan.

Djarwadi, Radik, CS., 1972.

Naskah Sedjarah Corps Hasanuddin, Prajurit Tempur dan Pembangunan. Makassar: Corhas.

Harvey, Barbara S., 1989. Pemberontakan Kahar Muzakkar dari Tradisi ke DI/TII. Jakarta: Grafiti.

Harvey, Barbara S., 1990. 
"Sulawesi Selatan: Boneka dan Patriot", dalam Audrey R. Kahin, Pergolakan Daerah Pada Awal Kemerdekaan. Jakarta: Grafiti.

Ijzereef, Willem. 1984.

De Zuid-Celebes Affaire, Kapitein Westerling en de Standrechtelijke Executies. Dieren: Bataafcshe Leeuw.

Kadir, Harun, et. al. 1984.

Sejarah

Perjuangan

Kemerdekaan Indonesia di Sulawesi Selatan 1945-1950.

Ujung Pandang: Kerjasama Unhas dengan Pemda Tk. I Propinsi Sulawesi Selatan.

Kartodirdjo, Sartono. 1992.

Pendekatan Ilmu Sosial dalam Metodelogi Sejarah. Jakarta: Gramedia.
Kementerian Penerangan Indonesia, 1953. Propinsi Sulawesi.

Poelinggomang, Edward L., 1995. Strategi Politik Pemerintah Kolonial Belanda dan Peristiwa Sulawesi Selatan. Makalah Seminar Sejarah RegionalRevolusi Kemerdekaan Indonesia di Sulawesi Selatan, Kerjasama Balai Kajian Sejarah dan Nilai Tradisional dan MSI Cabang Sulawesi Selatan.

Schiller, A. Arthur, 1995.

The Formation of Federal Indonesia. The Hague/Bandung: W. Van Hoeve Ltd.

Staatsblad van Nederlandsch Indie 1936 No. 68 dan 1938 No. 264. 